\title{
Virtual Screening for Biomimetic Anti-Cancer Peptides from Cordyceps militaris Putative Pepsinized Peptidome and Validation on Colon Cancer Cell Line
}

\author{
Jarinyagon Chantawannakul ${ }^{1}$, Paninnuch Chatpattanasiri ${ }^{1}$, Vichugorn Wattayagorn ${ }^{2}$, Mesayamas Kongsema ${ }^{2}$, \\ Tipanart Noikaew ${ }^{3, *}$ and Pramote Chumnanpuen ${ }^{2,4, *(D)}$
}

1 Mahidol Wittayanusorn School, 364 Salaya, Phuttamonthon District, Nakhon Prathom 73170, Thailand; kiwi.jarinyagon@gmail.com (J.C.); paninnuch.1@gmail.com (P.C.)

2 Department of Zoology, Faculty of Science, Kasetsart University, Bangkok 10900, Thailand; vichugorn.wa@ku.th (V.W.); fscimmk@ku.ac.th (M.K.)

3 Department of Biology and Health Science, Mahidol Wittayanusorn School, 364 Salaya, Phuttamonthon District, Nakhon Prathom 73170, Thailand

4 Omics Center for Agriculture, Bioresources, Food and Health, Kasetsart University (OmiKU), Bangkok 10900, Thailand

* Correspondence: tipanart.noi@mwit.ac.th (T.N.); pramote.c@ku.th (P.C.)

check for updates

Citation: Chantawannakul, J.; Chatpattanasiri, P.; Wattayagorn, V.; Kongsema, M.; Noikaew, T; Chumnanpuen, P. Virtual Screening for Biomimetic Anti-Cancer Peptides from Cordyceps militaris Putative Pepsinized Peptidome and Validation on Colon Cancer Cell Line. Molecules 2021, 26, 5767. https://doi.org/ $10.3390 /$ molecules 26195767

Academic Editors: Sabina Podlewska, Rita Guedes, Stanisław Jastrzębski and Wolfgang Sippl

Received: 3 July 2021

Accepted: 19 September 2021

Published: 23 September 2021

Publisher's Note: MDPI stays neutral with regard to jurisdictional claims in published maps and institutional affiliations.

Copyright: () 2021 by the authors. Licensee MDPI, Basel, Switzerland. This article is an open access article distributed under the terms and conditions of the Creative Commons Attribution (CC BY) license (https:// creativecommons.org/licenses/by/ $4.0 /)$.

\begin{abstract}
Colorectal cancer is one of the leading causes of cancer-related death in Thailand and many other countries. The standard practice for curing this cancer is surgery with an adjuvant chemotherapy treatment. However, the unfavorable side effects of chemotherapeutic drugs are undeniable. Recently, protein hydrolysates and anticancer peptides have become popular alternative options for colon cancer treatment. Therefore, we aimed to screen and select the anticancer peptide candidates from the in silico pepsin hydrolysate of a Cordyceps militaris (CM) proteome using machinelearning-based prediction servers for anticancer prediction, i.e., AntiCP, iACP, and MLACP. The selected CM-anticancer peptide candidates could be an alternative treatment or co-treatment agent for colorectal cancer, reducing the use of chemotherapeutic drugs. To ensure the anticancer properties, an in vitro assay was performed with "CM-biomimetic peptides" on the non-metastatic colon cancer cell line (HT-29). According to the 3-(4,5-dimethylthiazol-2-yl)-2,5-diphenyltetrazolium bromide (MTT) assay results from peptide candidate treatments at $0-400 \mu \mathrm{M}$, the $\mathrm{IC}_{50}$ doses of the CM-biomimetic peptide with no toxic and cancer-cell-penetrating ability, original C. militaris biomimetic peptide (C-ori), against the HT-29 cell line were $114.9 \mu \mathrm{M}$ at 72 hours. The effects of C-ori compared to the doxorubicin, a conventional chemotherapeutic drug for colon cancer treatment, and the combination effects of both the CM-anticancer peptide and doxorubicin were observed. The results showed that $\mathrm{C}$-ori increased the overall efficiency in the combination treatment with doxorubicin. According to the acridine orange/propidium iodine (AO/PI) staining assay, C-ori can induce apoptosis in HT-29 cells significantly, confirmed by chromatin condensation, membrane blebbing, apoptotic bodies, and late apoptosis which were observed under a fluorescence microscope.
\end{abstract}

Keywords: Cordyceps militaris; bioinformatics; colorectal cancer; chemotherapy; apoptosis

\section{Introduction}

Colorectal cancer is the third most common cancer globally [1]. Even though the standard treatments, such as surgery and radiotherapy, can effectively treat several cancer cases, chemotherapy is the most common treatment performed on advanced metastasis diseases. [2]. However, chemotherapeutic drugs typically aim to destroy rapidly dividing cells and inadvertently attack healthy cells and tissues, which results in a considerable number of unfavorable side effects [3]. The advent of modern molecular biology brought short peptides which could inhibit a wide range of microbes (bacteria and fungi) [4]. After a considerable number of peptides that expressed antimicrobial and antifungal 
activity were accumulated, cationic peptides with a low molecular weight were also shown to have special functions as anticancer peptides (ACPs). ACPs are a series of short peptides composed of 10-60 amino acids that can suppress tumor cell proliferation and expression [5]. ACPs have advantages over the conventional chemotherapy as they possess unique mechanisms, which lead to better inhibition of cell proliferation, migration, and angiogenesis [6]. ACPs have been reported to have a high cell penetration and low drug resistance; as such, the clinical application of ACPs is promising. Furthermore, the synthesis and modification of ACPs are inexpensive [7]. As a result, ACPs are becoming an alternative treatment or co-treatment with conventional chemotherapeutic agents in clinical use $[8,9]$

Cordyceps militaris (CM) has been widely used as a nutrient supplement in eastern Asia, and is extensively applied in modern medical therapeutic methods [10]. CM peptides are reported to have anticancer activities toward breast, lung, and bladder cancers, although the anticancer activities of CM peptides against colorectal cancer remains unclear [11]. Because of the time, laboring, and the exorbitant procedures that have to be conducted in order to identify CM ACPs, the computational method is an effective alternative to reduce expenses.

In this study, we proposed the use of support vector machine (SVM)-based predictors and the ensemble approach to identify the potential ACP candidates from the Cordyceps militaris peptide dataset. AntiCP utilized the amino acid composition and binary features, with SVM algorithm support, to classify the ACPs. The database of AntiCP was based on a dataset of 225 antimicrobial peptides (AMPs) with anticancer properties and random peptides from SwissProt (https:/ /www.expasy.org/resources/uniprotkb-swiss-prot, accessed on 12 May 2021) [12]. Another SVM-based predictor, iACP, classified the ACPs based on sequence information (i.e., amino acid composition, dipeptide composition, atomic composition, and physiochemical properties) [13]. MLACP developed the use of a random forest and an SVM machine learning approach to predict ACPs using sequence information [14]. These predictors could effectively screen the potential ACPs from a considerable number of natural peptides.

Even though ACPs have many advantages, they also contain many shortcomings which diminish the peptides' efficiency [15]. The reconstruction and modification of ACPs are needed to reduce their side effects and improve their therapeutical properties. The reconstructions are mainly main chain reconstructions and side chain modifications. The main chain reconstructions involve the change of natural and non-natural amino acids, whereas the side change modifications consist of cholesterol modification, phosphorylation, glycosylation, and palmitoylation $[16,17]$. The replacement of natural amino acids was utilized in this study as it had great significance on the structure and function of the peptides. The amino acid substitution also allowed us to examine the effects of each amino acid and dipeptide on the properties of the peptides [18].

To evaluate the anticancer activities of the anticancer candidate peptides, in vitro methods were utilized to confirm viability inhibition against colon cancer cell lines. The fluorescence measurement was also used to investigate the activity of peptides against the cells and identify the modes of action. Thus, our bioinformatic analysis provided ACP identification from nearly twenty thousand peptides, and the in vitro result showed the effects of peptides on cell lines.

\section{Results}

\subsection{Putative Anticancer Peptides Screening Using Computational Method}

The peptides were predicted to be anti-cancer peptides (ACPs) if: the cut off criteria at the support vector machine (SVM) score was over 1.00 in AntiCP; the probability was over 0.5 in iACP; and the scores of both random forest (RF) and SVM probabilities were over 0.5 . As a result, AntiCP predicted 20,525 ACPs; iACP predicted 3,739 ACPs; MLACP predicted 1,181 ACPs; and three prediction servers predicted 316 ACPs in common from 21,148 unique 
CM peptides. In terms of the peptides' properties (Figure 1), the majority of putative ACPs were 5-20 amino acids long (97.2\%), hydrophilic (72.8\%), and cationic (72.5\%).

(a)

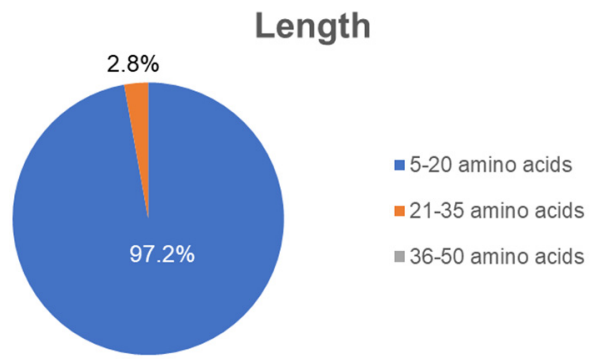

Hydrophobicity

(b)

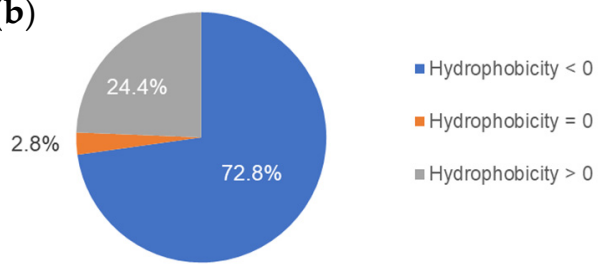

(c)

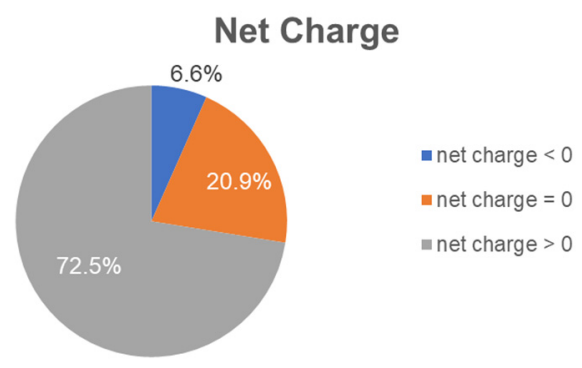

Figure 1. Percentage of the peptides' properties regarding their (a) length, (b) hydrophobicity, and (c) net charge from 316 putative ACPs.

ToxinPred (https://webs.iiitd.edu.in/raghava/toxinpred/protein.php, accessed on 12 May 2021) and MLCPP (http:/ / www.thegleelab.org/MLCPP, accessed on 12 May 2021) were used to predict the modes of action of the putative ACPs. ToxinPred predicted the toxicity of peptides against cancerous cells, while MLCPP predicted the cell penetration ability of peptides against cancer. Both ToxinPred and MLCPP predicted 14 peptides to be toxic ACPs; 242 peptides to be cell-penetrating ACPs; 5 peptides to have both modes of action; and 55 peptides to have no mode of action. We were interested to investigate the difference in the effects between peptides with no modes of action and with both modes of action.

From all five peptides having both modes of action, TTMICLTCAR was among the predicted peptides with highest prediction scores (SVM score, RF obability, (RF-ACP), and SVM-ACP). As a result, TTMICLTCAR was the candidate for the original toxic and cancer cell-penetrating peptide named "CTP-ori". CTP-ori had ten amino acids consisting of three polar uncharged threonines, two cysteines, and one positive charged arginine. CTP-ori was a hydrophilic, amphiphilic, and cationic peptide. To increase the prediction score, CTP-ori was re-designed by substituting certain amino acid residues using the peptide design option on AntiCP. CTP-ori was modified into a CM-biomimetic toxic and cancer cell penetration peptide, or "CTP-rds", by replacing methionine and alanine with glycine and cysteine, respectively (TTGICLTCCR) (Table 1).

Table 1. Anticancer prediction scores from 3 machine-learning-based prediction programs: AntiCP; iACP; and MLACP. The red highlighted letters indicate the amino acid substitutions.

\begin{tabular}{|c|c|c|c|c|c|c|}
\hline \multicolumn{3}{|c|}{ Peptide } & \multirow{2}{*}{ SVM Score } & \multirow{2}{*}{$\begin{array}{l}\text { RF } \\
\text { Probability }\end{array}$} & \multirow{2}{*}{ RF-ACP } & \multirow{2}{*}{ SVM-ACP } \\
\hline Group & Name & Sequence & & & & \\
\hline \multirow{2}{*}{$\begin{array}{l}\text { The toxic and cancer cell-penetrating } \\
\text { anticancer peptide }\end{array}$} & CTP-ori & TTMICLTCAR & 1.05 & 0.997 & 0.515 & 0.766 \\
\hline & CTP-rds & TTGICLTCCR & 1.58 & 0.997 & 0.538 & 0.674 \\
\hline \multirow{2}{*}{ The anticancer peptide } & C-ori & VTFVLIAAK & 1.28 & 0.875 & 0.558 & 0.787 \\
\hline & C-rds & FTFVLLAAK & 1.62 & 0.943 & 0.506 & 0.541 \\
\hline
\end{tabular}


From all 55 peptides with no special mode of actions against cancer cells, VTFVLIAAK was the candidate for the original CM-biomimetic peptide named "C-ori". C-ori had nine amino acids with double alanine residues, one polar uncharged threonine, one aromatic residue (phenylalanine), and a positive charged lysine (VTFVLIAAK). The physiochemical properties of C-ori were hydrophobic, amphipathic, and cationic. The modified CMbiomimetic peptide, C-rds, was the result of AntiCP's modification by having the first valine and isoleucine replaced by phenylalanine and leucine, respectively (FTFVLLAAK) (Table 1).

In accordance with the bioinformatics prediction, we decided to synthesize four putative ACPs (TTMICLTCAR; TTGICLTCCR; VTFVLIAAK; and FTFVLLAAK).

All selected peptides' molecular structures were predicted using PEP-FOLD3.5. The C-ori was random coiled (Figure 2c), whereas the CTP-ori, CTP-rds, and C-rds were single helixes (Figure 2a,b,d).

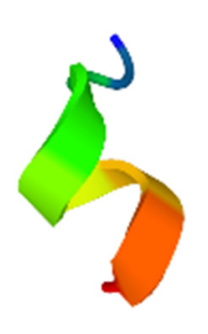

(a)

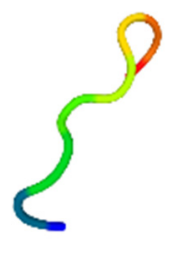

(c)

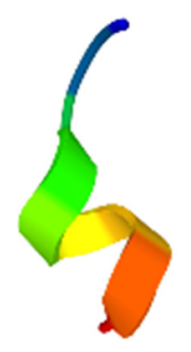

(b)

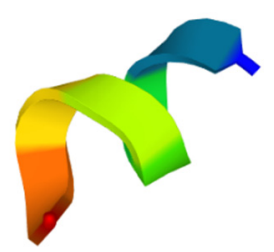

(d)

Figure 2. The molecular structure of: (a) the original CM-biomimetic toxic and cancer-cell-penetrating peptide, CTP-ori; (b) the modified CM-biomimetic toxic and cell-penetrating peptide, CTP-rds; (c) the original CM-biomimetic peptide, C-ori; (d) and the modified CM-biomimetic peptide, C-rds. The red end represents the $\mathrm{C}$-terminal, and the blue end represents the $\mathrm{N}$-terminal.

\subsection{The Inhibitory Effect of Selected Putative Anticancer Peptides against HT-29 Cell Line}

The inhibitory effects of putative ACP candidates were investigated using an MTT cell viability assay. The results showed that $\mathrm{C}$-ori decreased the cell viability of the HT-29 cell line in a dose-dependent manner with no effect on human dermal fibroblasts. The $\mathrm{IC}_{50}$ of C-ori was $114.9 \pm 1.5 \mu \mathrm{M}$ (Figure 3a). Contrarily, CTP-ori, CTP-rds (Supplementary Figure S1a,b), and C-rds (Figure 3b) showed no effect on the HT-29 cell line despite the increases in time and dose. 


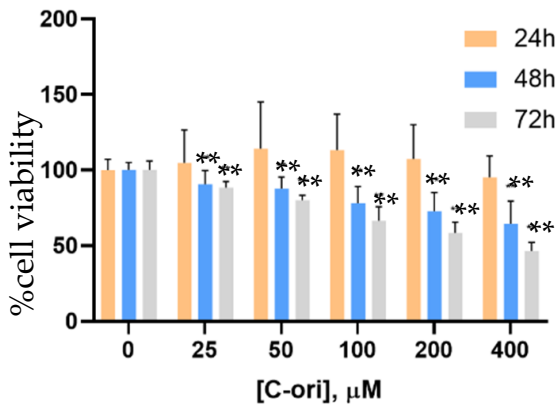

(a)

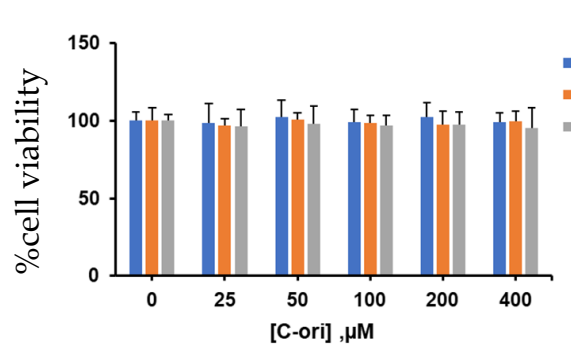

(c)

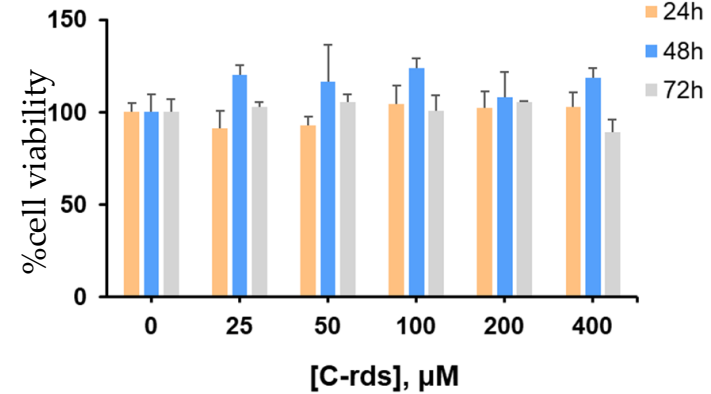

(b)

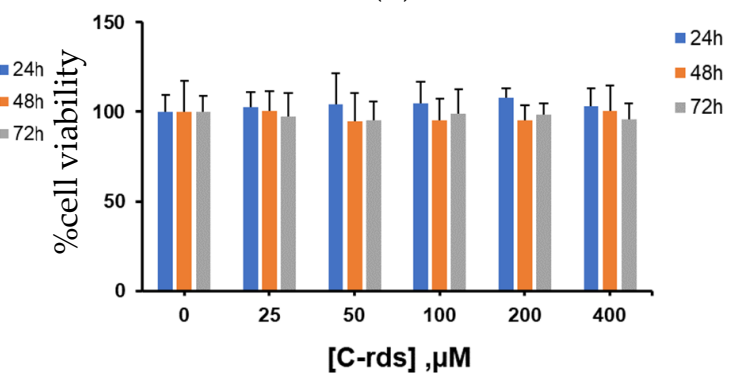

(d)

Figure 3. Inhibition of HT-29 cell viability treated by (a) C-ori and (b) C-rds. The cell viability of human dermal fibroblast cells treated by (c) C-ori and (d) C-rds. Cell viability was assessed by an MTT assay after a $24 \mathrm{~h}, 48 \mathrm{~h}$, and $72 \mathrm{~h}$ incubation with drugs. The results shown are mean $\pm \mathrm{SD}$; $n=4$ trials. $\left({ }^{* *} p<0.01\right)$.

\subsection{The Effects of the Original CM-Biomimetic Peptide and Doxorubicin against HT-29 Cell Line}

The original CM-biomimetic peptide's effects were compared with the conventional chemotherapeutic drug, doxorubicin, and the combination effects of both peptide and doxorubicin were observed. The $\mathrm{IC}_{50}$ of the doxorubicin ranged from 0.04 to $12 \mu \mathrm{M}$. According to Figure 4, the combination of the original CM-biomimetic peptide and doxorubicin showed a slightly increased effect against the HT-29 cell line.

HT-29 72h

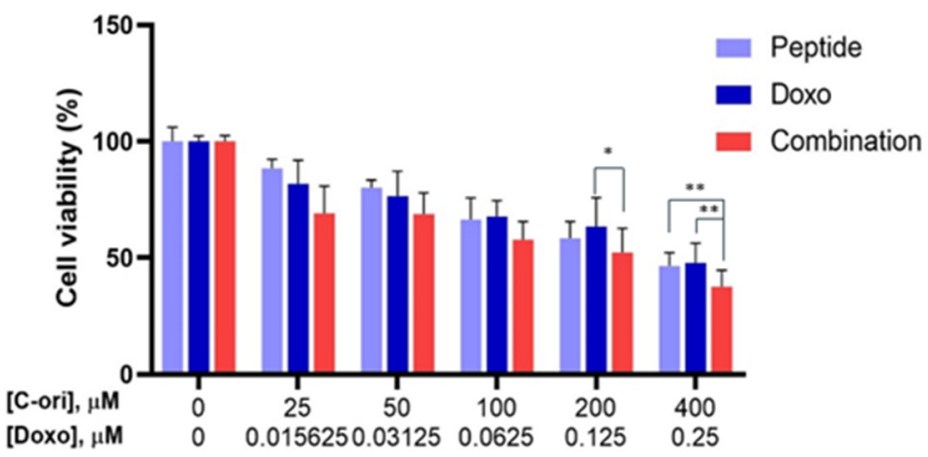

Figure 4. Combination effects of C-ori with doxorubicin on the HT-29 cell line. Cell viability was assessed using an MTT assay after a 72-hour incubation with drugs $\left({ }^{*} p<0.05,{ }^{* *} p<0.01\right)$.

2.4. The Effect of Original CM-Biomimetic Peptide and/or Doxorubicin on Apoptosis against HT-29 Cell Lines Using AO/PI Staining Assay

The apoptotic inductive effects of doxorubicin, C-ori, and the combination of both doxorubicin and C-ori on HT-29 were observed via morphological changes under a fluorescence microscope. The untreated HT-29 cells exhibited a rounded shape and an intact membrane displayed as a green fluorescence. Under the treated conditions, the morphology of HT-29 changed after the $72 \mathrm{~h}$ treatment of C-ori and $0.125 \mu \mathrm{M}$ doxorubicin with the 
presence of cell membrane blebbing, early apoptosis, and chromatin condensation. The cells that underwent late apoptosis were observed as a reddish-orange fluorescence after $72 \mathrm{~h}$ of the combination of doxorubicin, C-ori, and $0.25 \mu \mathrm{M}$ doxorubicin (Figures 5 and 6).
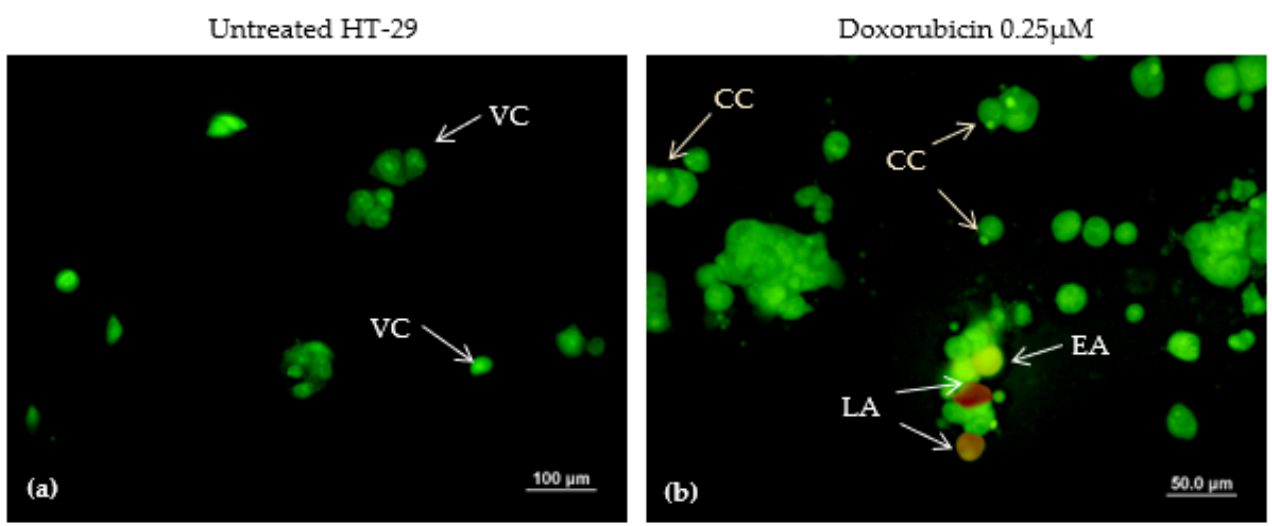

C-ori $400 \mu \mathrm{M}$

Doxorubicin $0.25 \mu \mathrm{M}+$ C-ori $400 \mu \mathrm{M}$
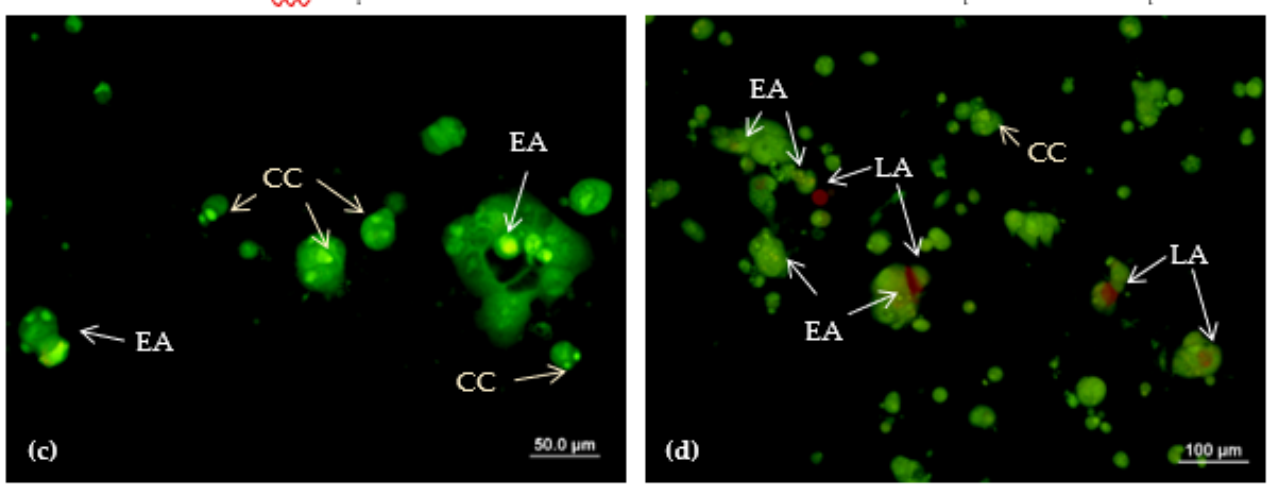

Figure 5. Acridine orange/propidium iodide double staining of HT-29 cells after $72 \mathrm{~h}$ exposure: (a) untreated (control); (b) $0.25 \mu \mathrm{M}$ doxorubicin; (c) $400 \mu \mathrm{M} \mathrm{C}$-ori; and (d) $0.25 \mu \mathrm{M}$ doxorubicin $+400 \mu \mathrm{M}$ C-ori. $\mathrm{VC}=$ viable cells; $\mathrm{BL}=$ membrane blebbing; $\mathrm{EA}=$ early apoptosis; $\mathrm{LA}=$ late apoptosis $\mathrm{CC}=$ chromosome condensation. Magnification: $40 \times$ and $100 \times$.
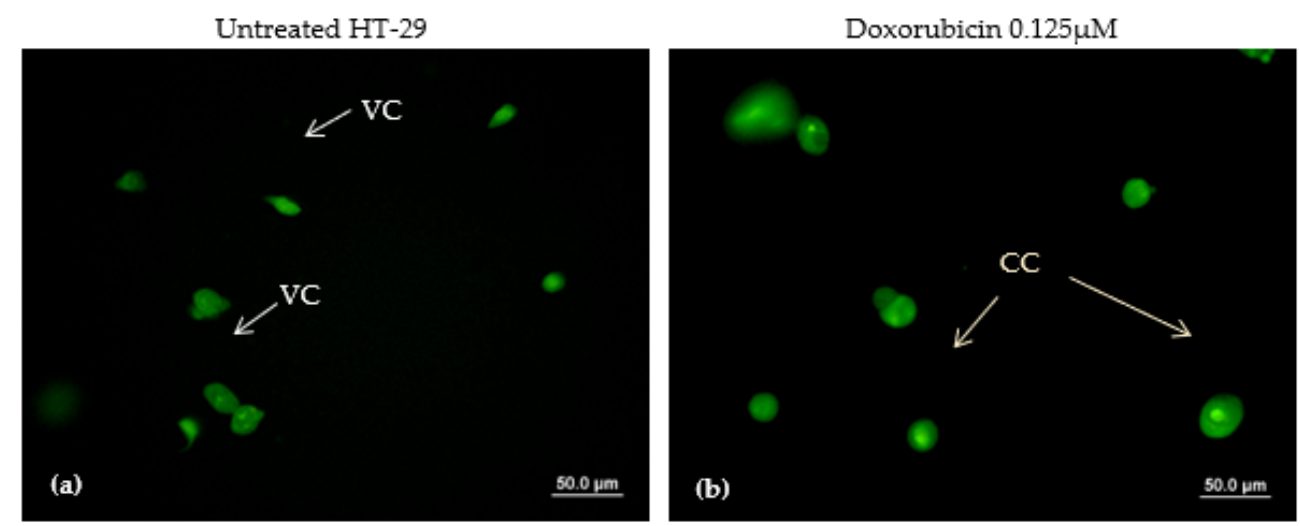

Figure 6. Cont. 

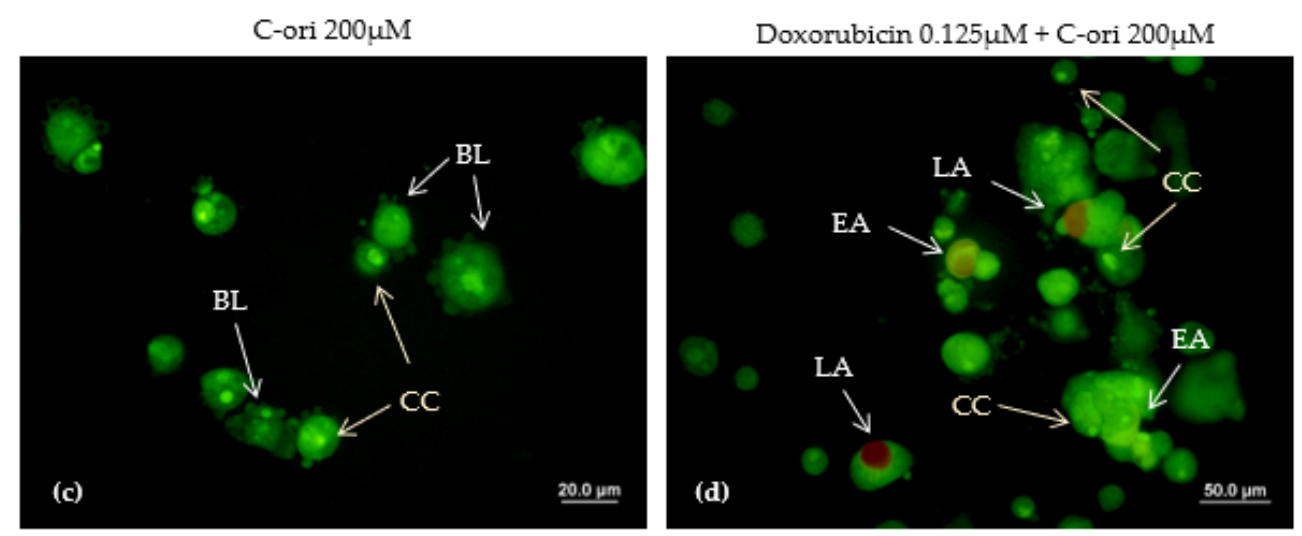

Figure 6. Acridine orange/propidium iodide double staining of HT-29 cells after $72 \mathrm{~h}$ exposure: (a) untreated (control); (b) $0.125 \mu \mathrm{M}$ doxorubicin; (c) $200 \mu \mathrm{M}$ C-ori; and (d) $0.125 \mu \mathrm{M}$ doxorubicin $+200 \mu \mathrm{M}$ C-ori. $\mathrm{VC}=$ viable cells; $\mathrm{BL}=$ membrane blebbing; $\mathrm{EA}=$ early apoptosis; $\mathrm{LA}=$ late apoptosis $\mathrm{CC}=$ chromosome condensation. Magnification: $40 \times$ and $100 \times$.

\section{Discussion}

The ACPs acted against malignant cancer cells with either membrane-disrupting processes or mitochondrial disruptions $[9,19]$. The net charge, amphiphilicity, and hydrophobicity were the key physiochemical properties for the ACPs to successfully disrupt the negative-charged cancer membrane and penetrate the cells. All mentioned physiochemical properties are indicated by their amino acid compositions [20,21]. Each of the selected putative ACPs possessed distinct properties: CTP-ori (TTMICLTCAR) was a hydrophilic, amphiphilic, and cationic peptide which was predicted to disturb the cancer cells with cytotoxicity and membrane-penetrating abilities; CTP-rds (TTGICLTCCR) shared the same characteristics with CTP-ori; C-ori (VTFVLIAAK) was a hydrophobic, amphiphilic, and cationic random coiled peptide. This peptide showed no toxicity nor cell-penetration abilities against the cancer cell, and was predicted by prediction servers named ToxinPred and MLCPP, respectively; C-rds (FTFVLLAAK) was a hydrophobic, amphiphilic, and cationic single helix peptide, and it possessed a potential non-toxic ability to penetrate the cancer cells.

Replacing the valine in C-ori with phenylalanine may have enhanced the cell membrane targeting, as phenylalanine is abundant in primary tumor membranes, and leucine residues are highly present in other reported ACPs [20,22-25]. Because of these reasons, C-rds was predicted with a higher prediction score in the in silico method. Nevertheless, the in vitro method indicated that only C-ori was effective in decreasing HT-29 cell viability. The possible reason for this phenomenon is that C-ori's amino acid composition (VTFVLIAAK) was rather specific to the HT-29 cell line. Changes or any substitution may have resulted in the failure to inhibit the cancer. Similarly, CTP-ori and CTP-rds were not effective in inhibiting the HT-29 cell line (supplementary Figures S1 and S2). Considering the prediction score of the CTP group and the $\mathrm{C}$ group, the SVM scores of the $\mathrm{C}$ group were well ahead those of the CTP group. Despite having two modes of action, the CTP group peptides were not the strongest candidates among all peptides from $\mathrm{CM}$, which may have made the peptides unable to successfully inhibit the cancers. However, the explanations behind these incidents will have to be further studied.

Doxorubicin is known to induce apoptosis in cancer cells [26,27]. The apoptosis characteristics in the HT-29 cell line are chromosome condensation (CC), apoptotic bodies $(\mathrm{AB})$, cell membrane blebbing (BL), early apoptosis (EA), and late apoptosis (LA) $[28,29]$. The effects of C-ori on the HT-29 cell line were similar to those of the doxorubicin according to the $\mathrm{AO} / \mathrm{PI}$ double staining assay, and C-ori was confirmed to induce apoptosis in the HT-29 cell line. Theoretically, the cationic properties of C-ori could establish non-specific interactions with the negatively charged phospholipids (e.g., phosphatidylglycerol) on cancer cells, which would cause an increase in cell permeability and destabilization of 
the membrane integrity [30-32]. As C-ori was predicted not to be able to disrupt cells intracellularly, its amino acid composition and physiochemical properties may have been the key to the destruction of cells through extracellular actions [33,34]. Furthermore, the decrease in the cholesterol in the cancer cells may have facilitated the apoptosis-induced ACPs to interact with the cells [35-37].

Even though there are countless modes of action ACPs can implement to inhibit cancer, some ACPs employ a similar model of the cell-disrupting process to those of antimicrobial peptides (AMPs) [38]. For example, magainin 2 is a bioactive peptide found in the skin secretions of amphibians, that is selective to solid tumors (e.g., the bladder cancer cell line), and utilizes a "carpet model" to destabilize the cells [39,40]. A "carpet-like model" could be the possible mode of action used by C-ori, as this model describes the interaction between positively charged peptides and anionic phospholipids on cancer cells, which means no penetration is involved. C-ori could remain parallel to the cell surface until it reached the critical concentration, and the barrier of the cells was thereafter weakened by the presence of C-ori [41]. Ultimately, the decrease in membrane permeability allowed C-ori to trigger apoptosis and the proliferation of HT-29 was inhibited [42]. However, further research is needed to further evaluate the apoptosis pathway of C-ori on specific molecular pathways, and also with other cancer cell types, e.g., metastasis colorectal cancer or other specific cancer cell lines. Moreover, the non-effective biomimetic ACPs candidates in our work might still have other potential uses as anti-cancer cells, e.g., cell cycle arrest or senescence induction, which are other modes of action that need further different types of cell and molecular analysis.

\section{Materials and Methods}

As can be seen in the pipeline illustrated in Figure 7, we proposed the bioinformatic virtual screening workflow with an in vitro validation start from stating the inputs of 21,148 putative unique peptide sequences until we selected the top predicted scores of unique $\mathrm{ACP}$ groups and multifunctional ACPs (with cytotoxicity and cell-penetrating abilities). Redesigns were also performed to improve the predicted scores, and the biomimetic peptides were experimentally tested with both the non-metastasis colorectal cancer cell line HT-29 and the human dermal fibroblast cell line to ensure the specific effects on cancer cell lines. 


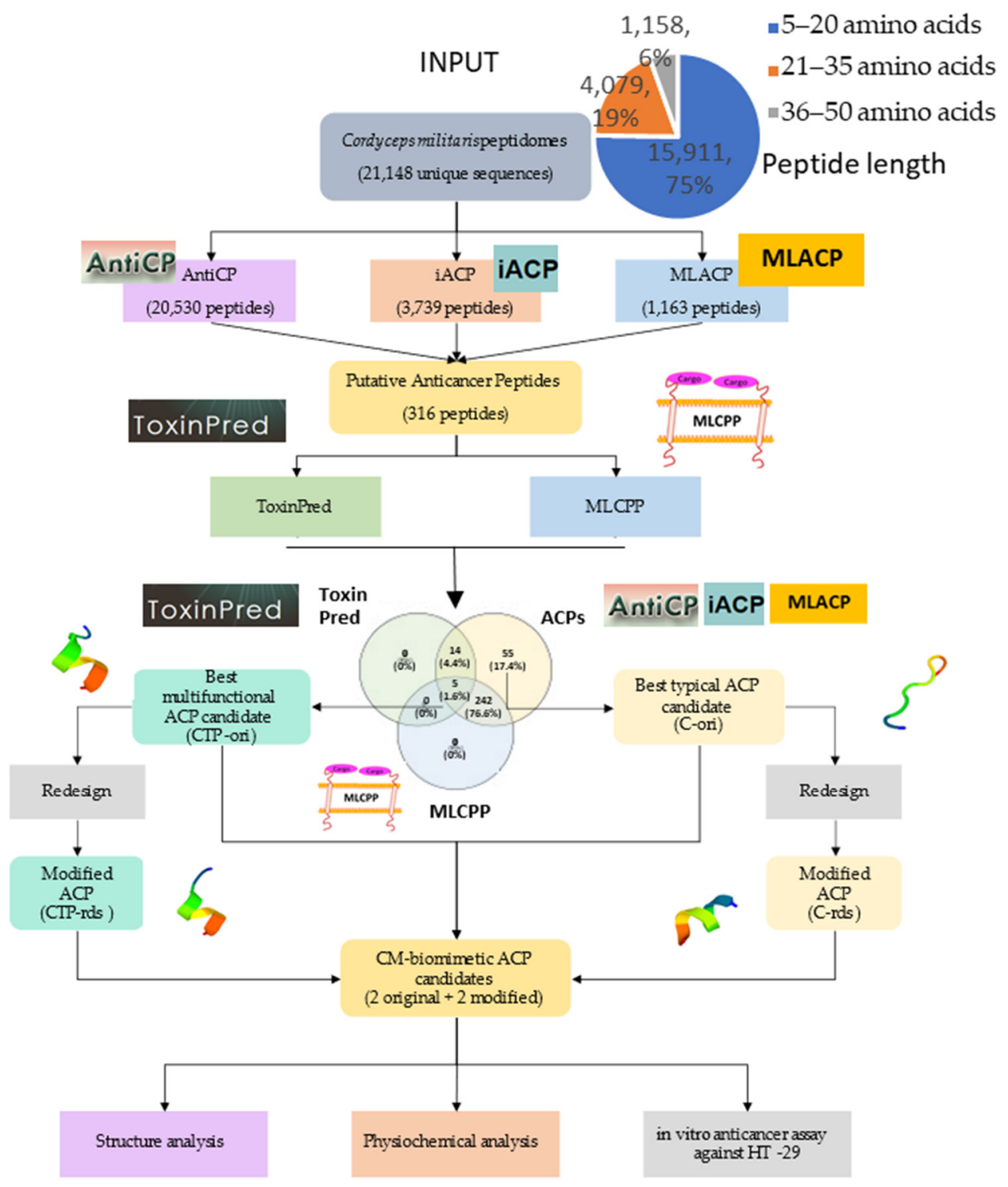

Figure 7. The workflow of the bioinformatic virtual screening for Cordyceps militaris (CM) anticancer peptide candidates, and the in vitro analysis of the colon cancer inhibition assay.

\subsection{The Bioinformatic Prediction of CM Peptides}

A total of 21,148 CM peptide sequences were obtained from the predicted cut site of the contig1 CM proteome (from the National Center for Biotechnology Information: $\mathrm{NCBI}$ ), and the in silico pepsin digestion was performed by our Python scripts. There were 3 groups of peptide length distributions, i.e., $5-20$ amino acid residues (15,911 sequences, $75 \%), 21-35$ amino acid residues (4,079 sequences, 19\%), and 36-50 amino acid residues $(1,158$ sequences, $6 \%)$ (Figure 7$)$. The peptide sequences were arranged in the FASTA format and were used as the input to predict anticancer properties using 3 machine-learningbased prediction servers, i.e., AntiCP (http://crdd.osdd.net/raghava/anticp, accessed on 12 May 2021), iACP (http:/ /lin-group.cn/server, accessed on 12 May 2021), and MLACP (http:/ / www.thegleelab.org/MLACP/MLACP.html, accessed on 12 May 2021). Venny 2.1.0. (https://bioinfogp.cnb.csic.es/tools/venny, accessed on 12 May 2021) was used to generate the Venn diagram to visualize the unique, dual, and multifunctional peptide candidates from each prediction online bioinformatic program. ToxinPred (https: / / webs. iiitd.edu.in/raghava/toxinpred/protein.php, accessed on 12 May 2021) and MLCPP ( http:/ / www.thegleelab.org/MLCPP, accessed on 12 May 2021) were used to predict whether the peptides were cytotoxic, or if they were cell-membrane-penetrating anti-cancer 
peptides or not. The selected putative ACPs were redesigned using AntiCP, utilizing the peptide design function. Lastly, PEP-FOLD3.0 (https:/ / bioserv.rpbs.univ-paris-diderot. $\mathrm{fr} /$ services/PEP-FOLD3, accessed on 15 May 2021) was used to simulate the feasible molecular structure of the peptides.

\subsection{Cell Culture}

The non-metastasis colorectal cancer cell line HT-29 and the human dermal fibroblast cell were kindly provided as a gift from Dr. Mattaka Khongkaw, senior researcher from National Nanotechnology Center (Nanotec) Thailand. HT-29 and the human dermal fibroblast cell were cultured and passaged in Dulbecco's Modified Eagle Medium (DMEM, GIBCO—Life Technologies, New York, NY, USA), and supplemented with a 10\% heatinactivated Fetal Bovine Serum (FBS, GIBCO-Life Technologies, NY) at $37^{\circ} \mathrm{C}$ under $5 \% \mathrm{CO}_{2}$.

\subsection{Determination of Cell Viability by MTT Assay}

The cell viability was evaluated by a conventional 3-(4,5-dimethylthiazol-2-yl)-2,5diphenyltetrazolium bromide (MTT) assay. The selected CM-biomimetic peptides were synthesized by Cellmano Biotech Limited (Hefei, China). The peptides were dissolved by dimethyl sulfoxide (DMSO, Sigma Aldrich, New York, NY, USA) until the final concentration was $100 \mathrm{mM}$. Cells were preincubated in 96-well plates at $2 \times 10^{5}$ cells/well (100 $\mu \mathrm{L} /$ well) for $24 \mathrm{~h}$, and treated with indicated concentrations of C-ori and C-rds (0 to $400 \mu \mathrm{M}$ ) for $24 \mathrm{~h}, 48 \mathrm{~h}$, and $72 \mathrm{~h}$, while the cells were treated with CTP-ori and CTP-rds at a different range of concentrations $(0$ to $100 \mu \mathrm{M})$ due to the limited quantity of the peptides. After it was due, MTT was added to each well with the same concentration of $1 \mathrm{mg} / \mathrm{mL}$ ( $10 \mu \mathrm{L} /$ well) and was further incubated for $4 \mathrm{~h}$. The media were removed and $100 \mu \mathrm{L}$ of DMSO was added to dissolve the purple crystal. Absorbance was measured at $570 \mathrm{~nm}$ using the absorbance microplate reader, PowerWave HT (BioTek Instruments, Berlin, Germany). The cell viability was calculated using the following formula:

$$
\% \text { cell viability }=\frac{\text { corrected absorbance of treated cells }}{\text { corrected absorbance of control cells }} \times 100
$$

The half-maximal inhibitory concentration $\left(\mathrm{IC}_{50}\right)$ was estimated by fitting the data with the non-linear regression equation.

\subsection{Statistical Analysis of the MTT Assay}

Each experiment was conducted at least three times. The data were presented as means $\pm \mathrm{SD}$ (standard deviation) if not stated otherwise. The parameters were analyzed with a one-way analysis of variance (one-way ANOVA) followed by Dunnett's multiple comparisons test. Graphpad Prism Version 9.0 (Graphpad Software, California, CA, USA) was utilized to conduct all statistical analysis. The values of $p<0.05$ and $p<0.01$ indicated that the differences were statistically significant or highly significant, respectively, when compared to the control group.

\subsection{Analysis of the Effect of Combination of Peptide and Doxorubicin}

The chemotherapy drug, doxorubicin hydrochloride (Tokyo Chemical Industry, Tokyo, Japan), was used to compare the effects with the selected peptide. The condition of the setting experiment was similar to the cell viability determination method. The cells were treated with different concentrations of doxorubicin $(0$ to $0.25 \mu \mathrm{M})$ in a two-fold manner to determine the cytotoxicity of doxorubicin. The combination of C-ori $(0$ to $400 \mu \mathrm{M})$ and doxorubicin $(0$ to $0.25 \mu \mathrm{M})$ was treated on cells in a two-fold manner to observe the effect of the combination. The cell viability was evaluated using an MTT assay following the above-mentioned procedures in Section 4.3. 


\subsection{Cell Morphological Study by AO/PI Staining Assay}

An acridine orange/propidium iodine (AO/PI) double staining assay was employed to determine the effects of the peptides on the HT-29 cancer cell death. HT-29 was seeded in an 8-well plate at $5 \times 10^{4}$ cells/well $\left(400 \mu \mathrm{L} /\right.$ well), and was allowed to adhere at $37^{\circ} \mathrm{C}$ in a $95 \%$ relative humidified incubator containing $5 \% \mathrm{CO}_{2}$ for $24 \mathrm{~h}$. The HT-29 was exposed to different concentrations of various drugs (control; DMSO; doxorubicin $0.25 \mu \mathrm{M}$; doxorubicin $0.125 \mu \mathrm{M}$; C-ori $400 \mu \mathrm{M}$, C-ori $200 \mu \mathrm{M}$; doxorubicin $0.25 \mu \mathrm{M}+$ C-ori $400 \mu \mathrm{M}$; and doxorubicin $0.125 \mu \mathrm{M}+\mathrm{C}$-ori $200 \mu \mathrm{M})$ for $72 \mathrm{~h}$. The adherent HT-29 cells were trypsinised and centrifuged (Hettich Universal 32 R centrifuge, DJB Labcare Ltd.,London, UK) at 1000 rpm at $4{ }^{\circ} \mathrm{C}$ for 10 minutes. The pallet was washed using phosphate-buffered saline (PBS), and re-centrifuged three times with $1000 \mu \mathrm{L}$ of PBS; afterwards, the PBS and waste were removed. Then, $5 \mu \mathrm{L}$ of PBS and $5 \mu \mathrm{L}$ of both $1 \mathrm{mg} / \mathrm{mL}$ acridine orange and $10 \mathrm{mg} / \mathrm{mL}$ propidium iodine were mixed with the pallet. The aliquots were visualized under a fluorescence microscope (Olympus, Berlin, Germany).

\section{Conclusions}

In conclusion, C-ori was the original pepsinized anticancer peptide from Cordyceps militaris which exhibited the apoptogenic effect against non-metastasis colorectal cell lines (HT-29). C-ori can be modified to increase the efficacy of peptides and can be developed to be used as a co-treatment with the conventional chemotherapy in clinical use. Even though the observed anticancer activity of the C-ori was rather weak and not quite suitable for further clinical trials, the anticancer activity of the designed peptide could be improved with drug delivery systems to be more specific to cancer cells with an improved uptake rate. Moreover, the non-effective biomimetic ACP candidates in our work might still have other potential uses as anti-cancer cells, e.g., cell cycle arrest or senescence induction, which are other modes of action that need further investigation. Furthermore, the mechanisms of C-ori in inhibiting other types of various cancer cell lines, as well as the in vivo method conducted on sample animals, have to be further studied.

Supplementary Materials: The following are available online, Figure S1: The effect of (a) CTP-ori and (b) CTP-rds on HT-29 cell viability assessed by MTT Assay, Figure S2: The effect of (a) CTP-ori and (b) CTP-rds on fibroblast cell viability assessed by MTT Assay.

Author Contributions: Conceptualization, P.C. and T.N.; methodology, M.K. and V.W.; software, P.C. (Pramote Chumnanpuen); validation, J.C., P.C. (Paninnuch Chatpattanasiri) and M.K.; formal analysis, J.C.; investigation, P.C. (Pramote Chumnanpuen) and M.K.; resources, P.C. (Pramote Chumnanpuen); data curation, J.C.; writing-original draft preparation, J.C.; writing-review and editing, P.C. (Pramote Chumnanpuen); visualization, J.C.; supervision, P.C. (Pramote Chumnanpuen); project administration, T.N.; funding acquisition, P.C. (Pramote Chumnanpuen). All authors have read and agreed to the published version of the manuscript.

Funding: This research was funded by the Mahidol Wittayanusorn School and the Department of Zoology, Faculty of Science, Kasetsart University, Thailand.

Institutional Review Board Statement: Not applicable.

Informed Consent Statement: Not applicable.

Data Availability Statement: Not applicable.

Acknowledgments: The authors would like to thank Mahidol Wittayanusorn School and Department of Zoology, Faculty of Science, Kasetsart University, for support all research facilities and equipment.

Conflicts of Interest: The authors declare no conflict of interest. The funders had no role in the design of the study; in the collection, analyses, or interpretation of data; in the writing of the manuscript, or in the decision to publish the results.

Sample Availability: Not applicable. 


\section{References}

1. Sun, C.-L.; Chen, L.; Xu, J.; Qu, W.; Guan, L.; Liu, W.-Y.; Akihisa, T.; Feng, F.; Zhang, J. Melanogenesis-Inhibitory and Antioxidant Activities of Phenolics from Periploca forrestii. Chem. Biodivers. 2017, 14, e1700083. [CrossRef] [PubMed]

2. Ewing, M.; Naredi, P.; Zhang, C.; Månsson, J. Identification of patients with non-metastatic colorectal cancer in primary care: A case-control study. Br. J. Gen. Pr. 2016, 66, e880-e886. [CrossRef]

3. $\mathrm{Wu}, \mathrm{X} . \mathrm{Z}$. A new classification system of anticancer drugs-Based on cell biological mechanisms. Med. Hypotheses 2006, 66, 883-887. [CrossRef] [PubMed]

4. Li, G.; Xia, X.; Long, Y.; Li, J.; Wu, J.; Zhu, Y. Research progresses and applications of antimicrobial peptides. Chin. J. Anim. Nutr. 2014, 26, 17-25. [CrossRef]

5. Qiao, X.; Wang, Y.; Yu, H. Progress in the mechanisms of anticancer peptides. Chin. J. Biotechnol. 2019, 35, 1391-1400. [CrossRef]

6. Hilchie, A.L.; Hoskin, D.W.; Coombs, M.R.P. Anticancer Activities of Natural and Synthetic Peptides. Adv. Exp. Med. Biol. 2019, 1117, 131-147. [CrossRef]

7. Pan, X.; Xu, J.; Jia, X. Research Progress Evaluating the Function and Mechanism of Anti-Tumor Peptides. Cancer Manag. Res. 2020, 12, 397-409. [CrossRef]

8. Kotamraju, S.; Konorev, E.A.; Joseph, J.; Kalyanaraman, B. Doxorubicin-induced Apoptosis in Endothelial Cells and Cardiomyocytes Is Ameliorated by Nitrone Spin Traps and Ebselen. J. Biol. Chem. 2000, 275, 33585-33592. [CrossRef] [PubMed]

9. Harris, F.; Dennison, S.R.; Singh, J.; Phoenix, D.A. On the selectivity and efficacy of defense peptides with respect to cancer cells. Med. Res. Rev. 2011, 33, 190-234. [CrossRef] [PubMed]

10. Chiangjong, W.; Chutipongtanate, S.; Hongeng, S. Anticancer peptide: Physicochemical property, functional aspect and trend in clinical application (Review). Int. J. Oncol. 2020, 57, 678-696. [CrossRef]

11. Das, S.K.; Masuda, M.; Sakurai, A.; Sakakibara, M. Medicinal uses of the mushroom Cordyceps militaris: Current state and prospects. Fitoterapia 2010, 81, 961-968. [CrossRef]

12. Tyagi, A.; Kapoor, P.; Kumar, R.; Chaudhary, K.; Gautam, A.; Raghava, G.P.S. In Silico Models for Designing and Discovering Novel Anticancer Peptides. Sci. Rep. 2013, 3, 1-8. [CrossRef] [PubMed]

13. Chen, W.; Ding, H.; Feng, P.; Lin, H.; Chou, K.-C. iACP: A sequence-based tool for identifying anticancer peptides. Oncotarget 2016, 7, 16895-16909. [CrossRef] [PubMed]

14. Manavalan, B.; Basith, S.; Shin, T.H.; Choi, S.; Kim, M.O.; Lee, G. MLACP: Machine-learning-based prediction of anticancer peptides. Oncotarget 2017, 8, 77121-77136. [CrossRef]

15. Xie, M.; Liu, D.; Yang, Y. Anti-cancer peptides: Classification, mechanism of action, reconstruction and modification. Open Biol. 2020, 10, 200004. [CrossRef]

16. Vlieghe, P.; Lisowski, V.; Martinez, J.; Khrestchatisky, M. Synthetic therapeutic peptides: Science and market. Drug Discov. Today 2010, 15, 40-56. [CrossRef] [PubMed]

17. Zhang, X.-X.; Eden, H.S.; Chen, X. Peptides in cancer nanomedicine: Drug carriers, targeting ligands and protease substrates. J. Control. Release 2012, 159, 2-13. [CrossRef] [PubMed]

18. Chen, Y.; Mant, C.T.; Farmer, S.W.; Hancock, R.; Vasil, M.L.; Hodges, R.S. Rational Design of $\alpha$-Helical Antimicrobial Peptides with Enhanced Activities and Specificity/Therapeutic Index. J. Biol. Chem. 2005, 280, 12316-12329. [CrossRef] [PubMed]

19. Kardani, K.; Bolhassani, A. Antimicrobial/anticancer peptides: Bioactive molecules and therapeutic agents. Immunotherapy 2021, 13, 669-684. [CrossRef] [PubMed]

20. Dennison, S.R.; Whittaker, M.; Harris, F.; Phoenix, D.A. Anticancer $\alpha$-Helical Peptides and Structure / Function Relationships Underpinning Their Interactions with Tumour Cell Membranes. Curr. Protein Pept. Sci. 2006, 7, 487-499. [CrossRef] [PubMed]

21. Huang, Y.; Wang, X.-F.; Wang, H.-Y.; Liu, Y.; Chen, Y. Studies on Mechanism of Action of Anticancer Peptides by Modulation of Hydrophobicity Within a Defined Structural Framework. Mol. Cancer Ther. 2011, 10, 416-426. [CrossRef] [PubMed]

22. Perry, S.R.; Hill, T.A.; de Araujo, A.D.; Hoang, H.N.; Fairlie, D.P. Contiguous hydrophobic and charged surface patches in short helix-constrained peptides drive cell permeability. Org. Biomol. Chem. 2017, 16, 367-371. [CrossRef]

23. Shoombuatong, W.; Schaduangrat, N.; Nantasenamat, C. Unraveling the bioactivity of anticancer peptides as deduced from machine learning. EXCLI J. 2018, 17, 734-752. [CrossRef]

24. Dai, Y.; Cai, X.; Shi, W.; Bi, X.; Su, X.; Pan, M.; Li, H.; Lin, H.; Huang, W.; Qian, H. Pro-apoptotic cationic host defense peptides rich in lysine or arginine to reverse drug resistance by disrupting tumor cell membrane. Amino Acids 2017, 49, 1601-1610. [CrossRef] [PubMed]

25. Gueron, G.; Anselmino, N.; Chiarella, P.; Ortiz, E.G.; Vickers, S.L.; Paez, A.V.; Giudice, J.; Contin, M.D.; Leonardi, D.; Jaworski, F.; et al. Game-changing restraint of Ros-damaged phenylalanine, upon tumor metastasis. Cell Death Dis. 2018, 9, 140. [CrossRef]

26. Mai, Y.; Yu, J.J.; Bartholdy, B.; Xu-Monette, Z.Y.; Knapp, E.E.; Yuan, F.; Chen, H.; Ding, B.B.; Yao, Z.; Das, B.; et al. An oxidative stress-based mechanism of doxorubicin cytotoxicity suggests new therapeutic strategies in ABC-DLBCL. Blood 2016, 128, 2797-2807. [CrossRef] [PubMed]

27. Wei, L.; Surma, M.; Gough, G.; Shi, S.; Lambert-Cheatham, N.; Chang, J.; Shi, J. Dissecting the Mechanisms of Doxorubicin and Oxidative Stress-Induced Cytotoxicity: The Involvement of Actin Cytoskeleton and ROCK1. PLoS ONE 2015, 10, e0131763. [CrossRef] [PubMed]

28. Wilson, C.A.; Browning, J.L. Death of HT29 adenocarcinoma cells induced by TNF family receptor activation is caspaseindependent and displays features of both apoptosis and necrosis. Cell Death Differ. 2002, 9, 1321-1333. [CrossRef] [PubMed]

29. Oberhammer, F.; Hochegger, K.; Fröschl, G.; Tiefenbacher, R.; Pavelka, M. Chromatin condensation during apoptosis is accompanied by degradation of lamin A + B, without enhanced activation of cdc2 kinase. J. Cell Biol. 1994, 126, 827-837. [CrossRef] [PubMed] 
30. Savini, F.; Loffredo, M.; Troiano, C.; Bobone, S.; Malanovic, N.; Eichmann, T.; Caprio, L.; Canale, V.; Park, Y.; Mangoni, M.; et al. Binding of an antimicrobial peptide to bacterial cells: Interaction with different species, strains and cellular components. Biochim. Biophys. Acta (BBA) Biomembr. 2020, 1862, 183291. [CrossRef]

31. Shai, Y. Mechanism of the binding, insertion and destabilization of phospholipid bilayer membranes by $\alpha$-helical antimicrobial and cell non-selective membrane-lytic peptides. Biochim. Biophys. Acta (BBA) Biomembr. 1999, 1462, 55-70. [CrossRef]

32. Travkova, O.G.; Moehwald, H.; Brezesinski, G. The interaction of antimicrobial peptides with membranes. Adv. Colloid Interface Sci. 2017, 247, 521-532. [CrossRef] [PubMed]

33. Baxter, A.A.; Lay, F.T.; Poon, I.K.H.; Kvansakul, M.; Hulett, M.D. Tumor cell membrane-targeting cationic antimicrobial peptides: Novel insights into mechanisms of action and therapeutic prospects. Experientia 2017, 74, 3809-3825. [CrossRef] [PubMed]

34. Roudi, R.; Syn, N.; Roudbary, M. Antimicrobial Peptides as Biologic and Immunotherapeutic Agents against Cancer: A Comprehensive Overview. Front. Immunol. 2017, 8, 1320. [CrossRef]

35. Baenke, F.; Peck, B.; Miess, H.; Schulze, A. Hooked on fat: The role of lipid synthesis in cancer metabolism and tumour development. Dis. Model. Mech. 2013, 6, 1353-1363. [CrossRef]

36. Accioly, M.T.; Pacheco, P.; Maya-Monteiro, C.M.; Carrossini, N.; Robbs, B.K.; Oliveira, S.S.; Kaufmann, C.; Morgado-Diaz, J.A.; Bozza, P.T.; Viola, J.P. Lipid Bodies Are Reservoirs of Cyclooxygenase-2 and Sites of Prostaglandin-E2Synthesis in Colon Cancer Cells. Cancer Res. 2008, 68, 1732-1740. [CrossRef]

37. Beloribi-Djefaflia, S.; Vasseur, S.; Guillaumond, F. Lipid metabolic reprogramming in cancer cells. Oncogenesis 2016, 5, e189. [CrossRef] [PubMed]

38. Tornesello, A.L.; Borrelli, A.; Buonaguro, L.; Buonaguro, F.M.; Tornesello, M.L. Antimicrobial Peptides as Anticancer Agents: Functional Properties and Biological Activities. Molecules 2020, 25, 2850. [CrossRef]

39. Lehmann, J.; Retz, M.; Sidhu, S.S.; Suttmann, H.; Sell, M.; Paulsen, F.; Harder, J.; Unteregger, G.; Stöckle, M. Antitumor Activity of the Antimicrobial Peptide Magainin II against Bladder Cancer Cell Lines. Eur. Urol. 2006, 50, 141-147. [CrossRef]

40. Oelkrug, C.; Hartke, M.; Schubert, A. Mode of action of anticancer peptides (ACPs) from amphibian origin. Anticancer. Res. 2015, 35, 635-643.

41. Borrelli, A.; Tornesello, A.L.; Tornesello, M.L.; Buonaguro, F.M. Cell Penetrating Peptides as Molecular Carriers for Anti-Cancer Agents. Molecules 2018, 23, 295. [CrossRef] [PubMed]

42. Lee, J.; Lee, D.G. Antimicrobial Peptides (AMPs) with Dual Mechanisms: Membrane Disruption and Apoptosis. J. Microbiol. Biotechnol. 2015, 25, 759-764. [CrossRef] [PubMed] 